\title{
Hydrothermal co-liquefaction of microalgae, wood, and sugar beet pulp
}

\author{
D. W. F. Brilman ${ }^{1}$ N. Drabik ${ }^{1,2}$ • M. Wądrzyk ${ }^{2}$
}

Received: 15 September 2016 / Revised: 11 January 2017 / Accepted: 18 January 2017 /Published online: 27 January 2017

(C) The Author(s) 2017. This article is published with open access at Springerlink.com

\begin{abstract}
Hydrothermal co-liquefaction of mixed (wet and dry) biomass residue streams would greatly enhance the viability and scale up potential of the technology as platform in bioenergy and biorefinery applications. This study aims to identify possible interaction effects between three different feeds (protein-rich microalgae, lignocellulosic wood, and carbohydrate-rich sugar beet pulp) and to broaden the data set for evaluating this concept. Co-liquefaction was evaluated at 250 and $350{ }^{\circ} \mathrm{C}$ at $10 \mathrm{~min}$ of holding time, using $10 \mathrm{wt} \%$ ( in water) binary mixtures (1:1 wt basis) and a (1:1:1 wt basis) ternary mixture. Results show that interaction during co-liquefaction does play a role and especially reduced the amount of biocrude produced. The biocrude yields obtained are around 15 and $40 \%$ below the estimated values for binary and ternary mixtures, on basis of linear averaging the results for the single feeds. For mixtures including algal biomass, a more than proportional nitrogen content and fraction of high molecular mass components was found in the biocrude. For the predictability of biocrude yield and composition in case of biomass mixtures, more work is needed to unravel these interactions.
\end{abstract}

Keywords Hydrothermal liquefaction - Microalgae · Co-feeding $\cdot$ Biomass $\cdot$ Mixtures

D. W. F. Brilman

d.w.f.brilman@utwente.nl

1 Faculty of Science and Technology, University of Twente, PO Box 217, 7500 AE Enschede, The Netherlands

2 Faculty of Energy and Fuels, AGH University of Science and Technology, al. Mickiewicza 30, 30-059 Kraków, Poland

\section{Introduction}

Hydrothermal processing of microalgae received in recent years a lot of attention, and not without reason; microalgae are one of the most promising bioresources for sustainable production of food and feed ingredients, high valuable chemicals, biofertilizer, and/or fuel components. The relatively high costs of cultivation can only be justified if the complete algal biomass production is valorized, either by whole-cell selling of microalgae or by producing multiple products for different markets, a so-called Algae Biorefinery. Due to the aqueous nature of the (algae) feed, hydrothermal processing is a natural choice as downstream technology for any residual algal biomass into energy carriers (biocrude and/or gaseous).

Hydrothermal liquefaction is a process in which aqueous slurries of biomass are brought to medium-high temperatures (200$375^{\circ} \mathrm{C}$ ) at elevated pressures (up to $25 \mathrm{MPa}$ ) to keep the water in the liquid state. Under these conditions, the biomass converts in this hot, compressed water into gaseous compounds, dissolved organics, an organic oil phase (called biocrude), and a residual solid fraction. The biocrude is the targeted liquid phase energy carrier. The dissolved organics can be used for heterotrophic growth of aquatic biomass or gasified in hot compressed water at even higher temperatures to recover energy and nutrients. The solids produced normally contain most of the mineral matter, coke, and unconverted biomass. The gas produced consists merely of $\mathrm{CO}_{2}$, and recycling thereof to the algae production stage seems to be a reasonable option.

With the worldwide increase of interest in algae cultivation and processing, new attention for hydrothermal processing arose [1]. Processing whole microalgae slurries showed that high oil yields and energy recoveries (even up to $75 \%$ for lowlipid algae) are attainable and detailed analyses of the biocrude compounds produced were carried out $[2,3]$. The biocrude produced is not directly suitable as transportation fuel but 
can be considered as renewable feed for co-feeding in existing refineries.

However, hydrothermal liquefaction based on microalgae alone will not make a significant impact on the fossil crude replacement in next decade, based on the current production levels of microalgae. Therefore, it will not be easy for the hydrothermal liquefaction of microalgae to achieve an economy of scale, which is required for successful entry in a bulk market as transportation fuels.

For most other biomass resources, like forest thinning, agricultural residues, manure-derived biomass, road-side grass and straw, bagasse etc., the amount of biomass available is more abundant, but its quantity and quality are fluctuating in time and place. Therefore, for the development of hydrothermal liquefaction as a viable platform technology, it would be of great advantage if microalgal biomass could be combined with different biomass sources to create a larger scale of operation and more continuity in operation (for seasonal bound resources).

Liquefaction of different biomasses in a single step process seems an attractive and simple solution, but understanding of the fundamentals of hydrothermal liquefaction and the effects of a changing feed composition is only starting to develop. The effect of microalgal composition was studied by Biller and Ross [4] and recently by Leow et al. [5]. Biller and Ross identified that in decreasing order, lipids $>$ proteins $>$ carbohydrates are converted to the biocrude product. They found that proteins and lipids were converted to biocrude efficiently without additional catalyst, whereas the biocrude yield from carbohydrates increases when using sodium carbonate as catalyst [4]. Leow et al. developed an improved component additivity model to predict biocrude yield on basis of lipid, protein, and carbohydrate content. In their approach, they used a single strain of microalgae, cultivated under varying conditions to vary its biochemical composition [5].

The liquefaction of microalgae was compared with that of other biomass sources by a few researchers. Vardon et al. studied the liquefaction of Spirulina and compared this with swine manure and anaerobic digested sludge [6]. They found a significant effect of the feed composition on the product distribution and biocrude composition. From their work, it was concluded that information on feed composition and a better understanding of the chemistry during liquefaction are needed to be able to predict biocrude yield and composition. Physical mixtures of these feeds were, however, not studied.

For wood-type biomass, the crude yield from liquefaction in water was found to be strongly related with the type and amount of lignin in the biomass [7]. The crude yield decreased linearly with the lignin content, whereas char yield increased linearly. When adding alkali salts, the liquefaction crude yields increased for most woody biomass types studied, but the linearity with lignin content disappeared. Remarkably, there was little effect on char yield. These differences were attributed to the different types of lignin present, and the results show once more that predicting hydrothermal liquefaction yields is not trivial.
Co-liquefaction of wood with glycerol was demonstrated in a continuous liquefaction setup by Pedersen et al. [8]. Their product analysis did not reveal to what extent glycerol was converted during processing and contributed to the biocrude. Chen et al. studied the co-liquefaction of swine manure with mixed algal biomass from waste water streams at $300^{\circ} \mathrm{C}$ with $1 \mathrm{~h}$ of reaction time [9]. With increasing swine manure content, the char yield decreased dramatically from around 60 to $17 \mathrm{wt} \%$, while the aqueous phase products showed a very distinct optimum at a $50 / 50 w / w$ feed ratio of manure/algal biomass. The biocrude product yield for a 50/50 w/w mixture could not be predicted from the experiments with algal mass and with swine manure alone. A similar result was found in the work by Xiu et al. [10] on the co-liquefaction of swine manure with vegetable oil.

In this work, new experimental results are presented for hydrothermal co-liquefaction of different biomass resources, alone and in mixtures. In this study, three distinctly different biomass types are subjected to liquefaction experiments. As biomass sources, pine wood (W), sugar extracted sugar beet pulp (S), and microalgae (A) were used. The pine wood was chosen to represent wood-type ligno-cellulosic biomass, and the (sugar extracted) sugar beet pulp is taken as carbohydrate-rich biomass. The experiments at different reaction time, different temperature, and with different feed composition are carried out to see to what extent the liquefaction of one feedstock influences the results of the other fractions in the feed mixture and to what extent the biocrude yield and composition can be predicted on basis of the results for the separate feed constituents.

This work is the start of a broader set of studies with mixed feedstocks, aiming to be able to predict the liquefaction products from mixed feeds and to optimize conversion conditions. The experimental results in this study should help to pave the way for hydrothermal liquefaction as single step process option for residue streams to produce a renewable, liquid energy carrier (biocrude).

\section{Materials and methods}

\subsection{Materials used}

As microalgae source, the freshwater species Desmodesmus sp. was used in this work. The microalgae were obtained as dry powder from a commercial source and identical to the feed used in earlier work $[2,3]$. The pine wood was obtained from Rettenmaier \& Söhne GmbH (Germany) and milled three times and sieved to a sieve fraction between 0.2 and $0.6 \mathrm{~mm}$. The composition of the pine wood used for this research is listed in Table 1. The sugar beet pulp used was purchased from Duynie B. V (The Netherlands), where sugar beet was cut and sugar was extracted. The remaining substance was pressed, dried, and finally pressed into pellets of $6 \mathrm{~mm}$. For this research, the sugar beet pulp was milled and separated by different particle size. The 
particle size $<0.3 \mathrm{~mm}$ was used. The $\mathrm{C}, \mathrm{N}$, and $\mathrm{H}$ contents were measured by elemental analysis (EA) using a Thermo Scientific Flash 2000 apparatus for CHN-S determination. The analysis of sugar beet pulp is listed in Table 1 .

\subsection{Methods}

HTL experiments were carried out using a 9-mL stainless steel autoclave, consisting of a cylinder with top and bottom openings. The 9-mL reactor was designed with very thin walls to allow for a fast heating rate $\left(\sim 300^{\circ} \mathrm{C} / \mathrm{min}\right)$. The autoclave can be rapidly heated up by immersing it in a hot fluidized sand bed and, after reaction, rapidly quenched again by submerging in cold water. The complete setup was located in an explosion-proof high-pressure safety room and essentially the same as used by Garcia Alba et al. [2], except for the reactor size.

The experimental procedure for liquefaction experiments starts by loading into the autoclave a pre-weighted amount of feedstock and water, typically around $0.400 \mathrm{~g}$ of biomass and $3.60 \mathrm{~g}$ water, resulting in $10 \mathrm{wt} \%$ biomass in water slurry. After loading the sample, the autoclave was tightly closed and connected to the pneumatic shaking piston. The gate valve from the reactor was tightly connected with a gas pipe. The autoclave

Table 1 Biomass feed analysis

\begin{tabular}{|c|c|c|c|}
\hline \multicolumn{2}{|c|}{ Biochemical composition (wt\%) } & \multicolumn{2}{|c|}{ Elemental composition (wt $\%$ ) } \\
\hline \multicolumn{4}{|l|}{ Desmodesmus sp. ${ }^{\mathrm{a}}$} \\
\hline Protein & $38-44$ & $\mathrm{C}^{\mathrm{b}}$ & 52.0 \\
\hline Lipid & $10-14$ & $\mathrm{H}^{\mathrm{b}}$ & 7.3 \\
\hline Fiber & $10-13$ & $\mathrm{~N}^{\mathrm{b}}$ & 6.9 \\
\hline Carbohydrate & $13-20$ & $\mathrm{O}^{\mathrm{c}}$ & 33.9 \\
\hline Ash content (dry matter) & 7.83 & $\mathrm{HHV}(\mathrm{MJ} / \mathrm{kg})^{\mathrm{b}}$ & 23.4 \\
\hline \multicolumn{4}{|l|}{ Pine Wood ${ }^{\mathrm{d}}$} \\
\hline Cellulose & 50.1 & $\mathrm{C}^{\mathrm{b}}$ & 46.6 \\
\hline Hemicellulose & 6.1 & $\mathrm{H}^{\mathrm{b}}$ & 6.3 \\
\hline Lignin & 28.0 & $\mathrm{~N}^{\mathrm{b}}$ & 0.1 \\
\hline \multirow[t]{2}{*}{ Ash content } & $<0.1$ & $\mathrm{O}^{\mathrm{c}}$ & 47.0 \\
\hline & & $\mathrm{HHV}(\mathrm{MJ} / \mathrm{kg})^{\mathrm{b}}$ & 20.4 \\
\hline Sugar beet pulp ${ }^{\mathrm{e}}$ & (indicative) & & $(\text { this work })^{\mathrm{f}}$ \\
\hline Cellulose & 30 & $\mathrm{C}$ & 38.6 \\
\hline Hemicellulose & 27 & $\mathrm{H}$ & 5.9 \\
\hline Protein & 11 & $\mathrm{~N}$ & 1.0 \\
\hline Pectin & 24 & $\mathrm{O}^{\mathrm{c}}$ & 54.5 \\
\hline Ash content & 4 & $\mathrm{HHV}(\mathrm{MJ} / \mathrm{kg})$ & 14.4 \\
\hline
\end{tabular}

${ }^{\mathrm{a}}$ Data from [1], from same batch

${ }^{\mathrm{b}}$ Dry, ash free basis

${ }^{\mathrm{c}}$ Calculated by difference as $100-(\mathrm{ash}+\mathrm{C}+\mathrm{N}+\mathrm{H})$

${ }^{\mathrm{d}}$ Data from [11]

${ }^{\mathrm{e}}$ Data from [12]

${ }^{\mathrm{f}}$ This work, after milling and sieving to $<0.3 \mathrm{~mm}$ (not d.a.f.) was flushed three times with $1 \mathrm{MPa}$ of nitrogen and pressurized to about $1 \mathrm{MPa}$. The experiment was controlled from outside the safety box via a control panel. The rotating shaking arm was turned on, and the autoclave was immersed into the top of fluidized sand bed. The moment of immersion in the sand bed marks the start of the reaction time. The heating time to the desired reaction temperature was within 1-2 min. After the desired reaction time, the reactor was lifted and quenched in a cold water bath; each time cooling was around $5 \mathrm{~min}$. After the reactor was cooled, the pressure inside was noted, and the gas in the autoclave was released carefully, to not loose liquid because of dissolved gas. Then, the product was collected after disconnecting and opening the top part of the reactor. Afterward, to collect the maximum amount of product, the autoclave was filled three times of $5 \mathrm{~mL}$ of dichloromethane (DCM, Sigma-Aldrich 99.8\% purity), closed, connected to the pneumatics shaker, and shaken in water bath ( 5 min each time). Then, the reactor was rinsed once more using $10 \mathrm{~mL}$ of solvent. Next, other parts of the setup (top of the reactor and gas pipe) were flushed with DCM to collect any remaining product.

The sample mixture was collected in a glass bottle and was vacuum filtrated over a $1-\mu \mathrm{m}$ pore size filter (Whatman GF/B). The glass bottle used to collect the sample from the reactor was washed three times with $5 \mathrm{~mL}$ of DCM. Next, the filter cake was also rinsed with $5 \mathrm{~mL}$ of dichloromethane, ensuring that the filter consisted of just solid residue. The solids were dried in the oven at $105{ }^{\circ} \mathrm{C}$ for $24 \mathrm{~h}$ and weighed. The filtrate was collected in a glass bottle and then was centrifuged at $9000 \mathrm{rpm}$ for $10 \mathrm{~min}$ to optimize the separation between the dichloromethane and water phase. The aqueous top phase was separated by aspiration using a syringe.

The water-soluble organics were quantified by evaporating the water phase at $70{ }^{\circ} \mathrm{C}$ for $24 \mathrm{~h}$, obtaining mixture of organics and ash soluble in water. This mixture was put into the oven at $550{ }^{\circ} \mathrm{C}$ for $5 \mathrm{~h}$ to quantify the ash content. The watersoluble organics were calculated by difference. For the organic dichloromethane fraction, the DCM was removed by evaporation by using vacuum oven with a cold trap system to collect the oil.

After the whole procedure, four products were obtained: biocrude oil (obtained from DCM-soluble fraction), gas, watersoluble organics, and solid residue. All steps are shown in Fig. 1.

Despite difficulties related to the small sample sizes used, the mass balance closure was in most cases on average $93 \mathrm{wt} \%$ and varied from 82 to $98 \mathrm{wt} \%$. A slight tendency was observed that mass balance closure was better at higher solid content, but no trends with temperature nor feed were found.

\subsection{Analysis}

The carbon, hydrogen, and nitrogen contents of biocrude products were determined with an elemental analyzer. The oxygen 


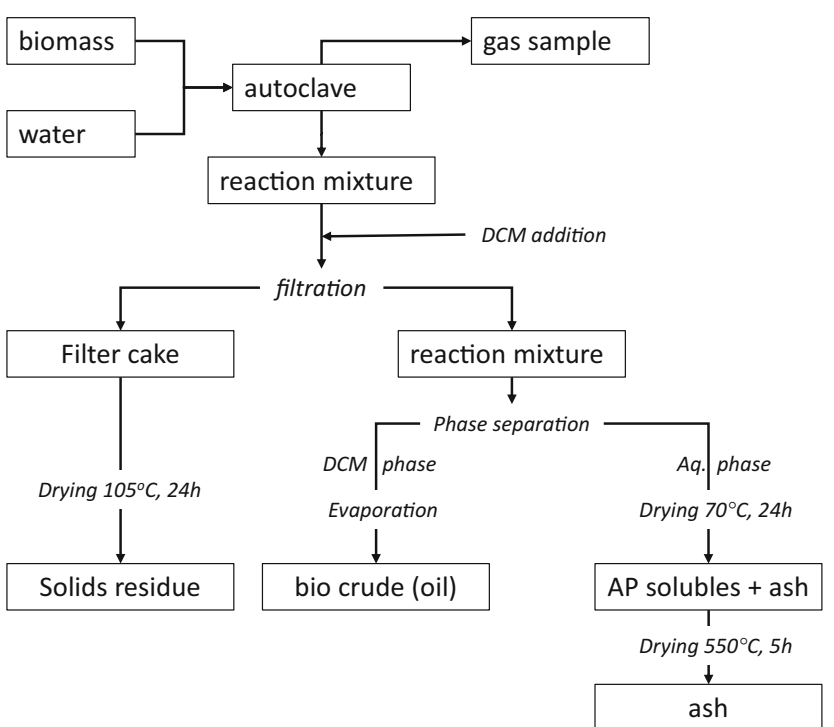

Fig. 1 Product recovery and separation procedure

content of the samples was calculated by difference. After elemental analysis, the weight percentages of $\mathrm{C}, \mathrm{H}, \mathrm{N}$, and $\mathrm{O}$ were used to calculate molar $\mathrm{H} / \mathrm{C}$ and $\mathrm{O} / \mathrm{C}$ ratio. The $\mathrm{HHV}$ for the biocrudes is calculated with the Reed's formula, see Eq. (1) [13].

$$
\begin{aligned}
\mathrm{HHV}(\mathrm{MJ} / \mathrm{kg}) & =0.35 \cdot \mathrm{C}(\mathrm{wt} \%)+1.18 \cdot \mathrm{H}(\mathrm{wt} \%) \\
& -0.1 \cdot \mathrm{O}(\mathrm{wt} \%)-0.02 \cdot \mathrm{N}(\mathrm{wt} \%)
\end{aligned}
$$

The energy recovery, from biomass to biocrude, is calculated using the following:

Energy Recovery $(\mathrm{ER})=\frac{\mathrm{HHV}_{\mathrm{oil}} \cdot \mathrm{m}_{\mathrm{oil}}}{\mathrm{HHV}_{\text {biomass }} \cdot \mathrm{m}_{\text {biomass }}}$

Gel permeation chromatography (GPC) is used to determine the molecular weight distribution of the bio-oil obtained after HTL. The bio-oil was dissolved in THF, filtered through $0.2 \mu \mathrm{m}$ syringe filter, and injected into the system. GPC analysis is performed using an Agilent 1200 series HPLC system with 3 GPC PLgel $3 \mu \mathrm{m}$ MIXED-E columns connected in series. The column temperature was $40{ }^{\circ} \mathrm{C}$, with a flow of $1 \mathrm{~mL} / \mathrm{min}$, with tetrahydrofuran (THF) being the solvent.

The biocrude was divided into the fractions referred to as "heavy" and "light" compounds. The light fraction is defined as all of the components in the biocrude with a $\mathrm{MW}_{\mathrm{GPC}}$ lower than $200 \mathrm{Da}$ and a heavy fraction, comprising compounds with a $\mathrm{MW}_{\mathrm{GPC}}$ higher than $1000 \mathrm{Da}$. The RID detector signal is plotted versus the elution time, and the area corresponding to the heavy or light fractions is divided by the total area.

Functional group compositional analysis was carried out in mid-infrared wavenumber range using FTIR spectrometry (Bruker), equipped with an attenuated total reflection system (ATR).

\section{Results and discussion}

\subsection{Product yields}

For each of the biomass types, separate liquefaction experiments were performed, prior to mixing the biomass types. All experiments were measured in duplo or triplo, and the results presented in Fig. 2 are the mean values with standard deviation. For all experiments, the biomass content of the slurry is $10 \mathrm{wt} \%$.

The results from Fig. 2 show already some clear differences between the different feeds. Wood produced the largest amount of solids and a relatively low amount of biocrude. Especially, the solids collected for the $250{ }^{\circ} \mathrm{C}$ run visually resembled the (unconverted) wood feed material. Microalgae clearly produced the largest amount of biocrude. It is also remarkable to see that some of the trends are different with respect to an increase in temperature. For all feeds, the biocrude and gas yield increase when going from 250 to $350{ }^{\circ} \mathrm{C}$. However, the aqueous phase organics (AP) decrease for algae and beet pulp, but increase for wood. Whereas the solid residue increased for sugar beet pulp, it strongly decreased for wood and algae as feed.

It seems that with increasing temperature for microalgae, the solids and aqueous phase organics are more converted into additional biocrude, whereas for beet pulp, more solids are formed probably because of secondary polymerization of the carbohydrate-derived decomposition products. For wood, the AP yield increases with temperature, which is probably related to an incomplete primary conversion of the biomass feed at $250{ }^{\circ} \mathrm{C}$. The results show that although sugar beet seems more easily converted (at lower temperature) than microalgae, the selectivity towards biocrude of the latter is much more favorable. Apparently, wood is most recalcitrant towards liquefaction, most likely related to its lignin content. The attractiveness of microalgae for biocrude production via HTL is clearly subscribed by the product distribution in Fig. 2, where the specific biocrude yield for microalgae at $350{ }^{\circ} \mathrm{C}$ is more than double the values obtained for pine wood and sugar beet pulp.

To evaluate possible interactions during hydrothermal liquefaction, $50 / 50 \mathrm{wt} \% / \mathrm{wt} \%$ mixtures of different combinations of the three feeds were made and used for liquefaction experiments. The results are presented in Fig. 3. The HTL product yields for these mixtures are compared in Fig. 3 with the weight-averaged yields based on the results of the separate feeds, see Eq. (3), as presented in Fig. 2.

In Eq. (3), $Y_{p, \text { mix }}$ is the estimated product yield (weight basis) for the mixture, with $\mathrm{P}=$ gas, aqueous phase organics, biocrude, or solids, and $\mathrm{w}_{\text {feed,i }}$ is the weight fraction of that feed type in the total feed mixture. $\mathrm{Y}_{\mathrm{p}, \mathrm{i}}$ is the corresponding product yield (for $\mathrm{p}=$ gas $/$ biocrude/AP/solids) as obtained for feedstock $\mathrm{i}$ (here: $\mathrm{i}=$ microalgae, sugar beet pulp, or pine wood). To correct for the (small) differences in the mass balance closure (MB) for the different experiments, the 
Fig. 2 Product yield for HTL of the separate feeds $(10 \mathrm{wt} \%$, 10 min reaction time). $A P$ aqueous phase organics, crude DCM-soluble liquefaction oil

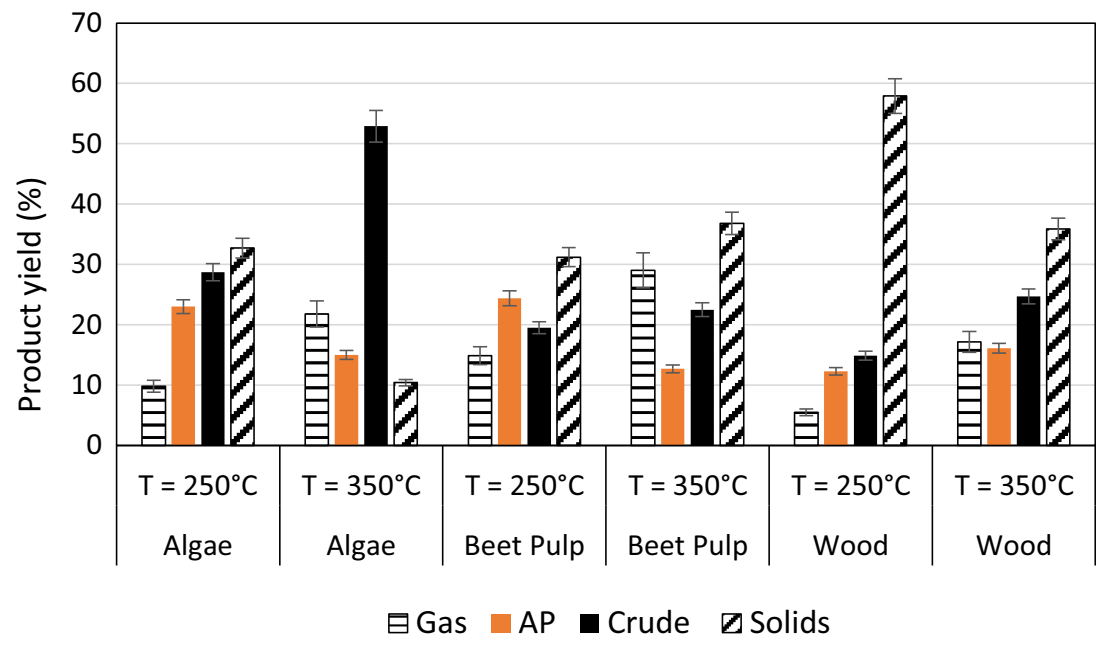

correction factor $\mathrm{MB}_{\text {mix }}$ over $\mathrm{MB}_{\mathrm{i}}$ is introduced. The average mass balance closure is $94 \%$ with a standard deviation of $4 \%$ and no trend towards operating temperature, feed type used, or single feeds vs binary mixtures.

$Y_{p, \text { mix }}=\sum_{i} w_{\text {feed }, i} \cdot \frac{Y_{p, i}}{M B_{i}} \cdot M B_{\text {mix }}=\sum_{i} w_{\text {feed }, i} \cdot Y_{p, i} \cdot \frac{\sum_{p} Y_{p, \text { mix }}}{\sum_{p} Y_{p, i}}$

This "linear averaging" model is found to be reasonable successful in predicting the product yields at $250^{\circ} \mathrm{C}$, but less successful in predicting the product yields for the $350{ }^{\circ} \mathrm{C}$ series. For the biocrude yield, which is the targeted product, the model significantly overpredicts the yield with a relative error of around $15 \%$, calculated via $\left(\mathrm{Y}_{\mathrm{p}, \text { mix }}-\mathrm{Y}_{\mathrm{p} \text {,exp. }}\right) / \mathrm{Y}_{\mathrm{p} \text {,exp. }}$, with $\mathrm{Y}_{\mathrm{p}, \text { exp. }}$ the experimental value.

In Table 2, the average deviations (for each product class, for all binary mixtures) between model predictions and actual yields are presented. From Table 2, it is clear that the prediction is less accurate at the higher temperature. The underpredicted AP yield and the overpredicted solid yield for the algae-sugar beet pulp combination (Fig. 3a) suggest an enhanced biomass decomposition in the presence of microalgae liquefaction products. For the pine wood-algae mixture, less biocrude was found than predicted at both temperatures, while the AP organics and gaseous product yields were higher than estimated. This suggests that the algae liquefaction products assist in breaking down the fragments produced during liquefaction of other biomasses.

Remarkably, the observed decrease in solid residue in Fig. 5a is not accompanied by an (expected) increase in biocrude yield. On the contrary, instead of a higher than expected (by linear averaging) biocrude yield, the biocrude yield is also overpredicted in these cases. The product class which benefits most from the reduced solids and biocrude yield is the aqueous phase organics.
For the mixture of the three feeds together (microalgae, pine wood, and sugar beet pulp; each one third on mass basis), the experimental results as well as the predicted yields by the linear model are presented in Fig. 4. Next to linear averaging of the results for the separate feeds, also a linear averaging of the results for the three binary mixtures was tested, but this did not significantly improve the predictions. As the experimental procedures for the separation of biocrude from the solids might have played a role, the estimation for these grouped classes is reported in Fig. $4 \mathrm{~b}$. It is found that for the $350{ }^{\circ} \mathrm{C}$ data, the higher than predicted yield of the fraction $\mathrm{AP}+$ gas is visible, beyond possible effects of incomplete solids/biocrude separation.

Most striking result in Fig. 4a is the strong overprediction (39\% at $250{ }^{\circ} \mathrm{C}$ and $47 \%$ at $350{ }^{\circ} \mathrm{C}$ ) of the crude oil yield. Since the mass balance closure of these experiments with the ternary mixtures was at the lower end of all experiments (90 wt $\%$ versus overall $94 \mathrm{wt} \% \pm 4 \%$ standard deviation), one is tempted to suggest that the incomplete mass balance closure is merely due to the crude fraction. There is, however, no reason to assume that in these mixed feed experiments, the error in the crude oil yield determination is larger than in the other experiments. Also, the reproducibility of these experiments was very good. A possible explanation for the lower mass balance closure could be that the mixture leads to the production of more light and volatile products in the aqueous phase (AP) and/or in the biocrude that are lost during solvent evaporation, but this would not affect the conclusion with respect to the biocrude yield.

The energy recovery, in the form of the targeted biocrude yield and its heating value, is for all mixtures less than expected by averaging the results of the single feeds, see Fig. 5. This effect is most pronounced for the ternary biomass mixed feed. It can be concluded that there is no synergetic effect observed for the energy recovery for mixing these biomass streams. The observed anti-synergetic effect underlines the importance of testing combinations of biomass feeds and improving our 
Fig. 3 HTL product yield for mixtures (50/50 by mass) vs estimation by linear averaging. a Sugar beet pulp-algae. b Algaepine wood. c Pine wood-sugar beet pulp

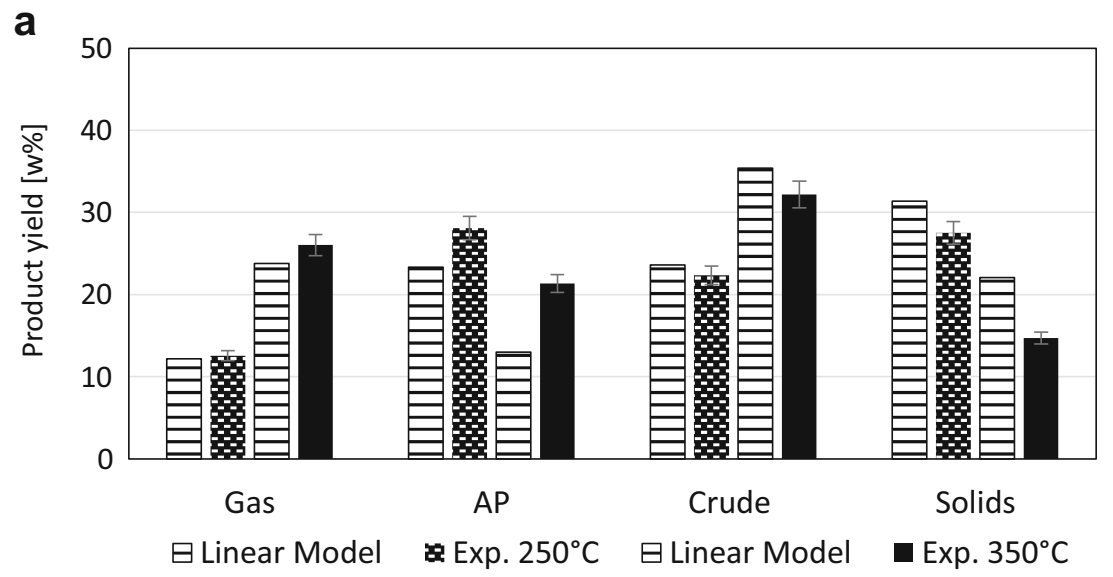

b
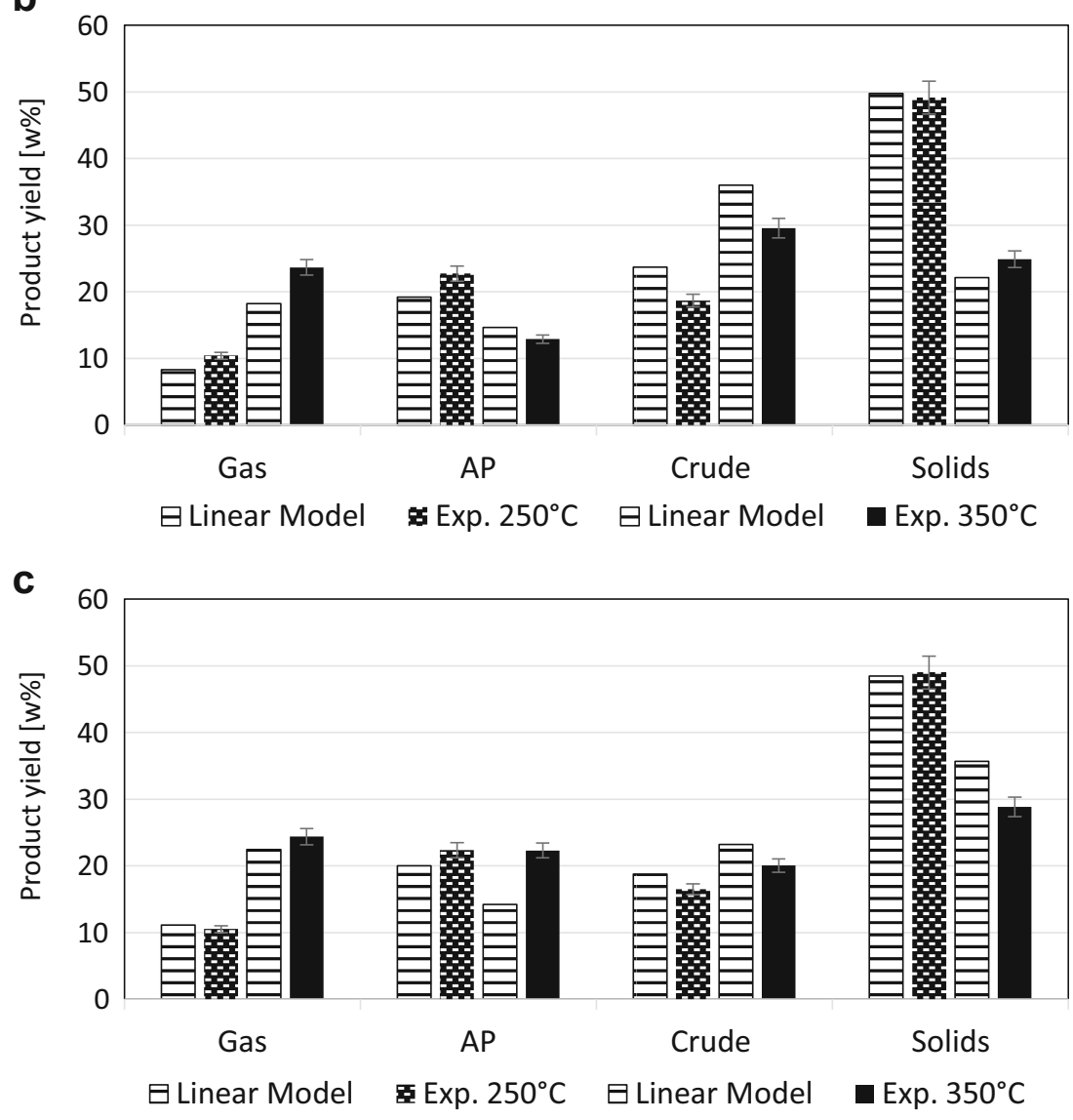

Table 2 Absolute and relative errors for the model prediction deviations for the binary mixtures

\begin{tabular}{llllll}
\hline & \multicolumn{2}{l}{ Av. relative errors } & & \multicolumn{2}{c}{ Av. deviation (\% points) } \\
\cline { 2 - 3 } \cline { 5 - 6 } \cline { 5 - 6 } & $T=250{ }^{\circ} \mathrm{C}$ & $T=350{ }^{\circ} \mathrm{C}$ & & $T=250{ }^{\circ} \mathrm{C}$ & $T=350{ }^{\circ} \mathrm{C}$ \\
\hline Gas & $-5.8 \%$ & $-13 \%$ & & -0.6 & -3.2 \\
AP & $-14 \%$ & $-21 \%$ & & -3.6 & -4.9 \\
Biocrude & $+15 \%$ & $+16 \%$ & & 2.8 & 4.3 \\
Solids & $+4.8 \%$ & $+21 \%$ & & 1.3 & 3.8 \\
\hline
\end{tabular}

understanding of underlying phenomena of the interactions in the further development of this platform technology.

\subsection{Product analysis}

The biocrudes produced by the hydrothermal liquefaction at different temperatures for the different feeds were subjected to GPC analysis, elemental analysis, and FT-IR spectroscopy. In Fig. 6, next to the crude yields, the nitrogen content and the higher heating values are reported in a comprehensive 
Fig. 4 HTL product yield for ternary mixtures $(1 / 3$ each by mass of pine wood, microalgae, and (extracted) sugar beet pulp) vs estimation by linear averaging for a each product class separately and $\mathbf{b}$ grouped product classes
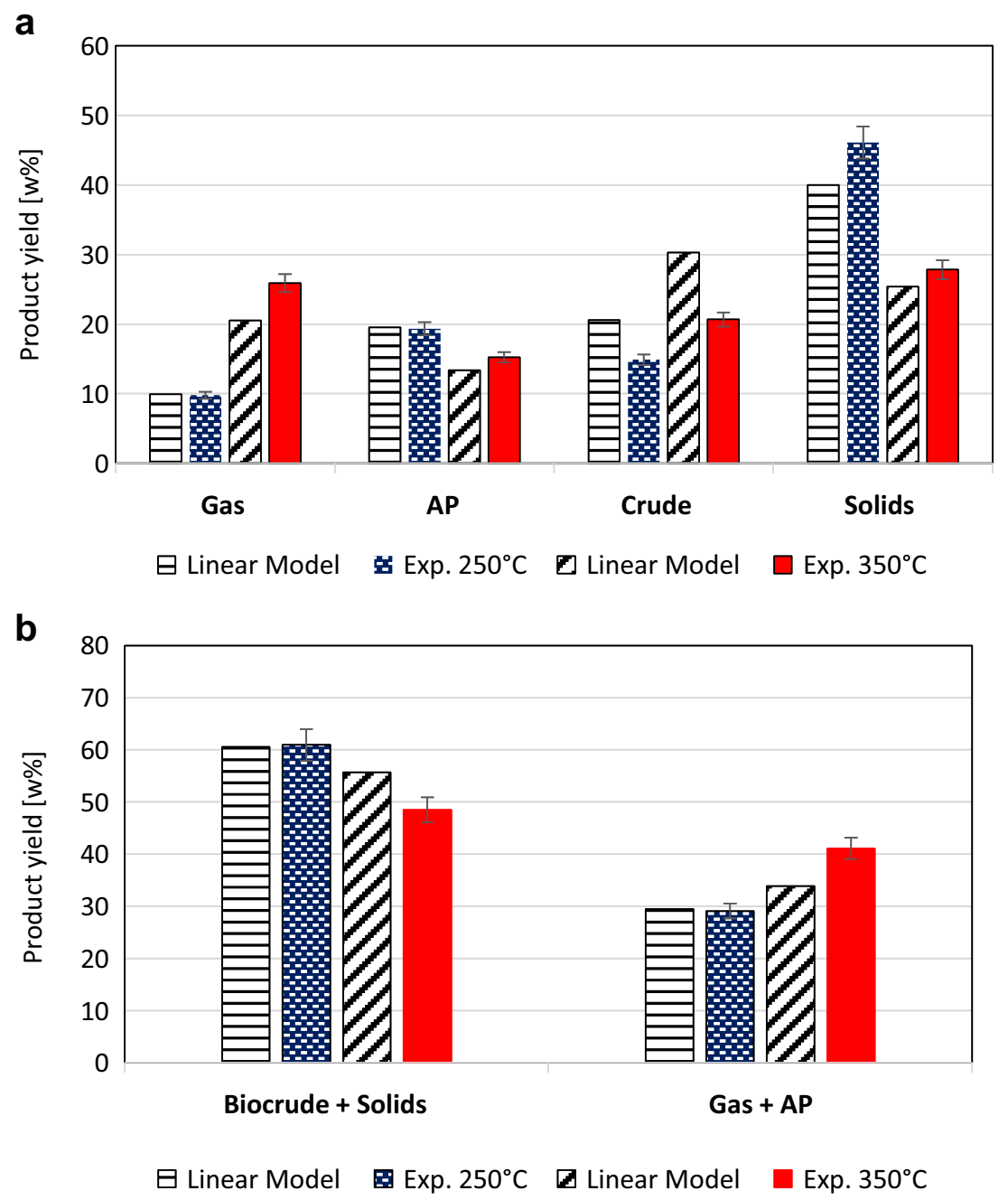

overview. It is clear that a high crude yield and high HHV are reached using algae as (part of the) feed. At these conditions, also the nitrogen level in the crude is relatively high. It furthermore shows that the application of microalgae in the feed leads to a relatively high content of "heavies," defined as GPC detectables with an apparent molar weight exceeding $1000 \mathrm{Da}$.
In Fig. 7, some characteristics of the biocrudes produced are compared with those for the biocrudes produced for the separate biomass feeds used. In Fig. 7a, the nitrogen content of the biocrude is presented. It is clear to see that the $\mathrm{N}$ content of the actual biocrudes exceeds the estimated value based on linear averaging of the contribution of the separate feeds for mixtures
Fig. 5 Energy recovery by the various HTL crudes produced from the single feeds, binary mixtures, and ternary mixture

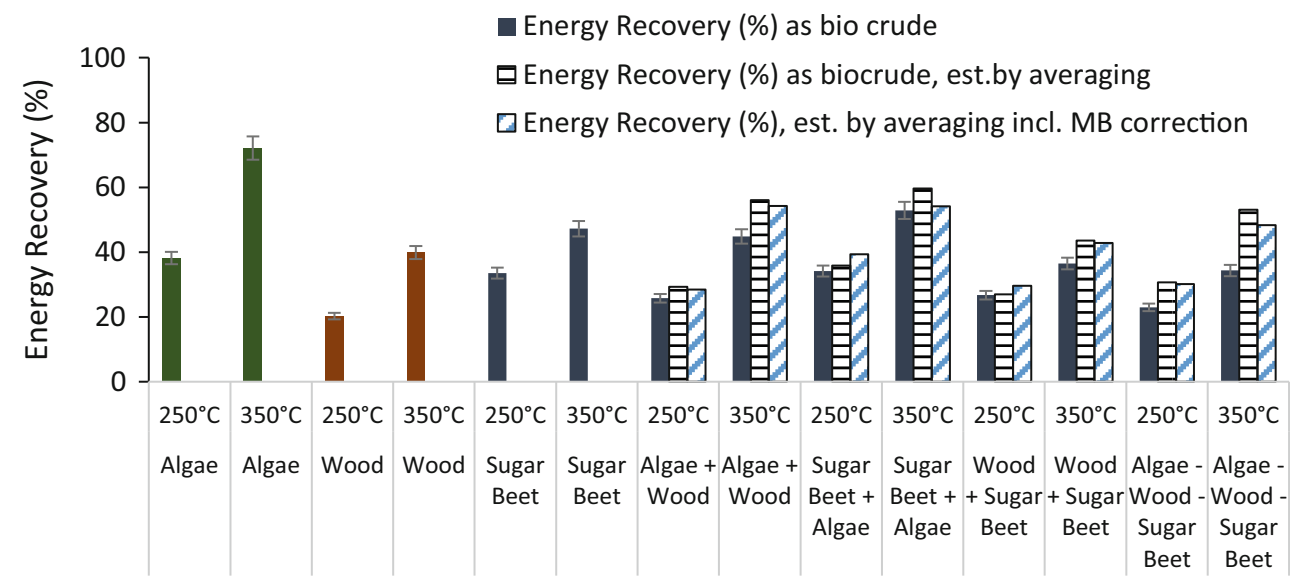




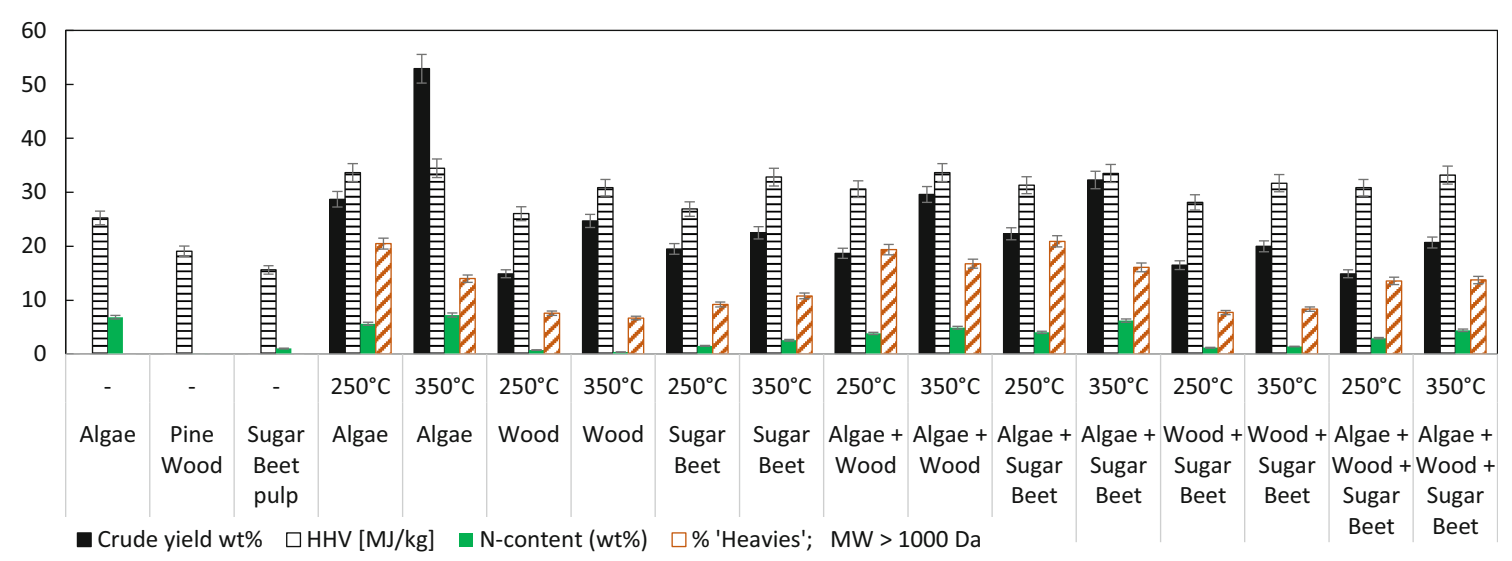

Fig. 6 Characteristics of HTL crudes for the various feeds and HTL temperatures. For reference, the data for the feeds (microalgae, extracted sugar beet pulp, and pine wood) are included

in which algal biomass is present. This suggests that the algalbased contribution to the biocrude is more than actual fraction of the algal biomass in the feed mixture. Especially when considering that the biocrude yields are (on average) some $15 \%$ less than estimated by the same linear averaging method.
In Fig. 7b, for the fraction heavies in the biocrude, this effect is even stronger. Biocrude from algal biomass containing mixtures has around $40 \%$ more heavies than estimated via linear averaging of the biocrudes for the separate feeds. This confirms that the algal-based contribution to the biocrude is more than the actual
Fig. 7 Nitrogen- and "heavies" content for biocrude from binary and ternary mixtures, compared to estimates based on linear averaging of results for the separate biomass constituents. a Nitrogen content. b Fraction "heavies" a

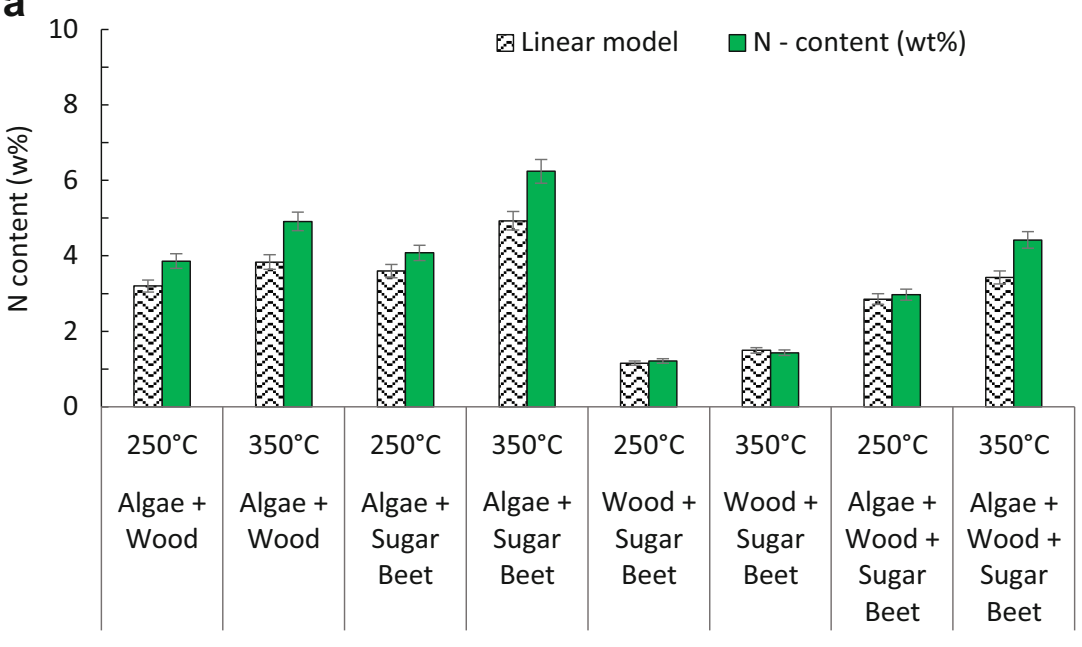

b

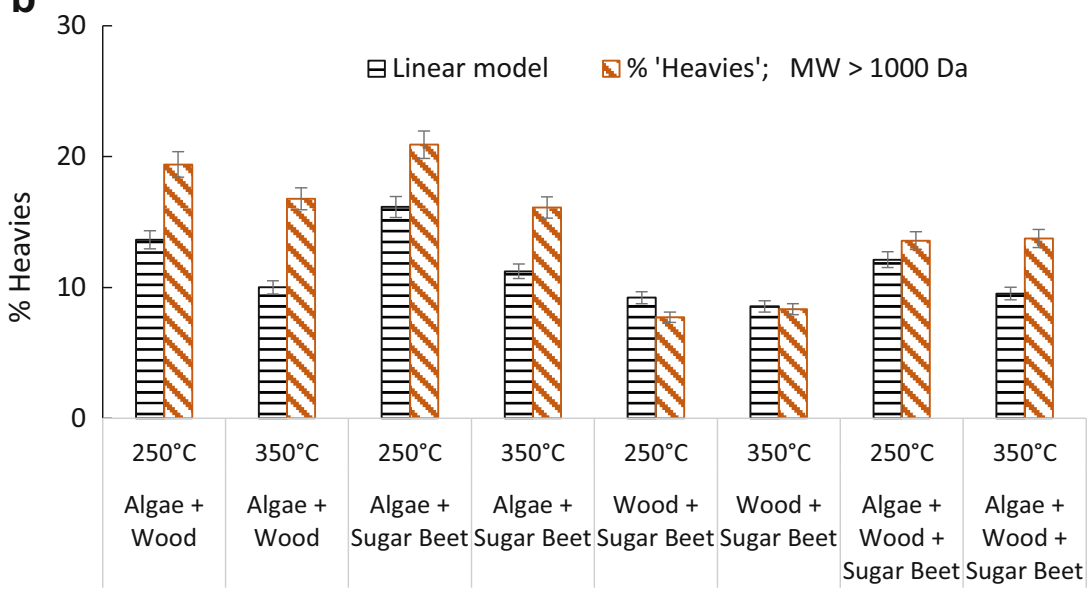



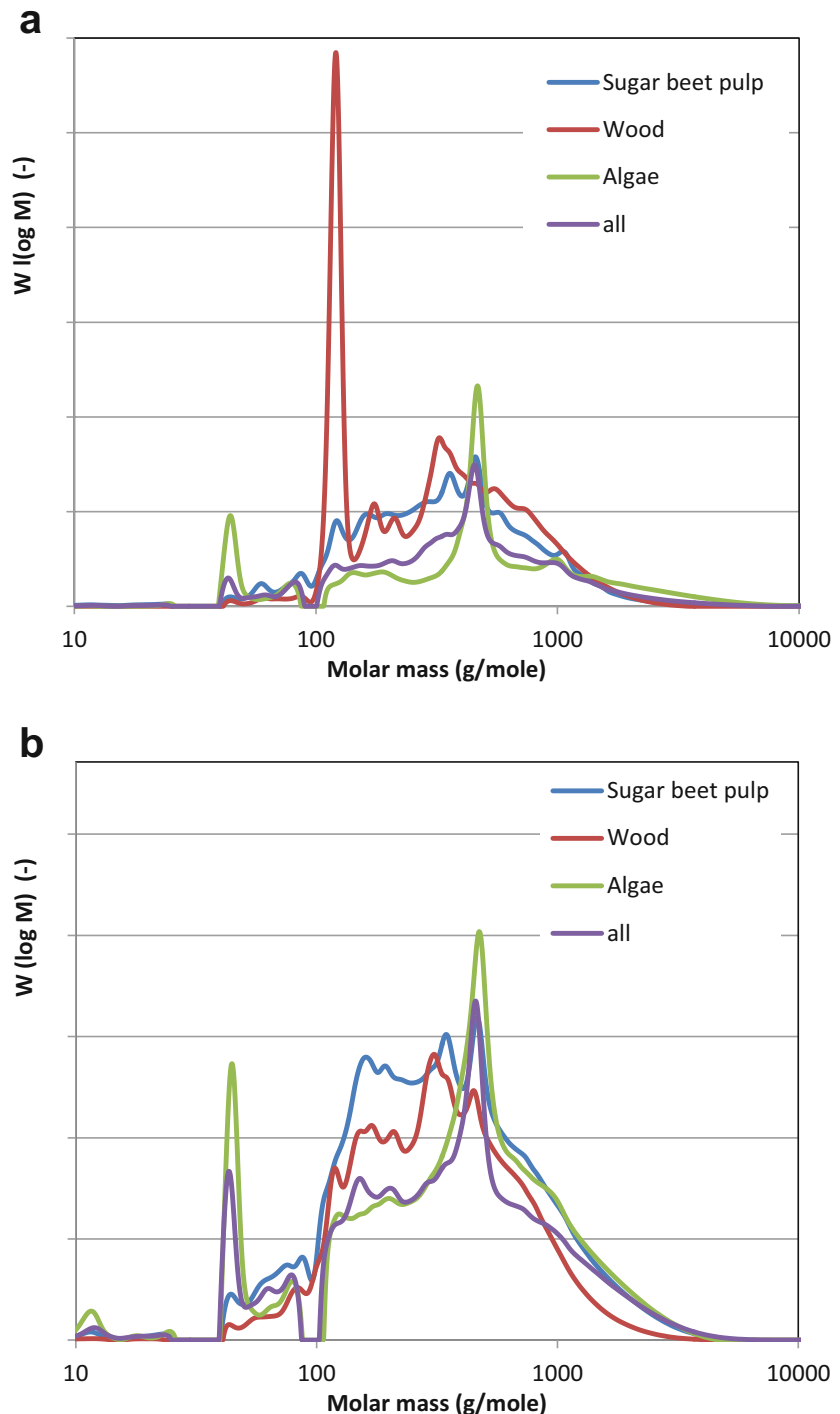

Fig. 8 Molecular weight distribution by GPC analysis for biocrudes obtained at a $250{ }^{\circ} \mathrm{C}$, b $350{ }^{\circ} \mathrm{C}$

fraction of the algal biomass in the feed mixture. It shows that (part of) the biocrude constituents in biocrude from algal biomass are larger than obtained from the other feeds tested, and considering the similarity between Fig. 7a, b, this heavies fraction has a significant N-content (protein-derived compounds). For the wood-sugar beet pulp mixture, the heavies fraction and Ncontent are very similar to the estimated values at both temperatures from the separate crudes, suggesting little interaction.

Figure 8a, b shows that the GPC profile of the crude obtained for the ternary mixture (all feeds) resembles most the one obtained for the crude obtained from the micro algae feed alone. This holds for the both the $250{ }^{\circ} \mathrm{C}$ HTL crudes as well as for the $350^{\circ} \mathrm{C}$ HTL crudes. Similar findings were observed in the GPC analysis of the binary mixtures. In mixtures in which algae were used as part of the feed, the GPC profile of the biocrude from the mixture is very similar to that of crude obtained by HTL of microalgae under the same conditions. For the sugar beet-pine wood mixture, hence without the microalgae, the profile was more an "average" of both. Comparing the FT-IR signals showed a more "mixed response" of the crudes produced from mixed feedstocks, in comparison with the FT-IR signals for the crudes based on the separate feeds.

\subsection{Discussion}

The results for the product yield show that for the different feeds, clearly different results are obtained with respect to product distribution (crude, solids, AP, and gas) and with respect to crude composition (as indicated by $\mathrm{N}$ content and heavies fraction). With increasing temperature under the HTL conditions studied (10-min reaction time and $10 \mathrm{wt} \%$ feed) in most cases, the solid yield for the feed mixtures is decreasing, suggesting that the solid feeds are more readily converted to smaller compounds, especially aqueous phase organics and gaseous compounds. From Fig. 7, it appears that the strongest interaction is for the feed mixtures containing algal biomass. The reason for this could be that microalgae (as it contains no recalcitrant lignin) decompose at lower temperatures than sugar beet pulp and pine wood. Hence, liquefaction products from the microalgae liquefaction may enhance liquefaction of the other biomasses by, e.g., catalyzing hydrolysis. Acetic acid is one of the compounds that may cause this effect. In an earlier study by Ramos-Tercero, the production of acetic acid from microalgae liquefaction is shown [14]. It was also shown that for a single biomass feed of microalgae, there was no correlation between acetic concentration and biocrude production. However, the hydrolysis of, e.g., compounds in the sugar beet pulp (Fig. 3a) to aqueous phase organics or the production of gaseous compounds from pine wood, may be enhanced by the higher acid concentration [15]. Considering that algal biomass-derived biocrude is more than proportionally represented in the biocrude of the mixture of algal biomass with pine wood (see Fig. 7a, b), it is even more surprising that the biocrude yield itself is less than based on linear averaging and illustrates the complexity of the interaction.

The results from Fig. 7 on the N-content and on heavies fraction, in combination with the reduced biocrude yield, clearly show that the co-liquefaction of algal biomass leads to enhanced decomposition of the other biomass components (pine wood, sugar beet pulp) tested into fragments that do not report to the DCM soluble biocrude fraction. More experimental work and more in-depth analysis of the chemical composition of biocrude and of the aqueous phase organics are required to identify more clearly the nature of the interaction. 


\section{Conclusions}

Hydrothermal liquefaction of three different biomass types (pine wood, microalgae, and extracted sugar beet pulp) at a relatively low $\left(250^{\circ} \mathrm{C}\right)$ and high $\left(350^{\circ} \mathrm{C}\right)$ temperature showed clearly that interactions occur during co-liquefaction of different biomass feed types. Mixing feeds resulted in all cases in lower than expected biocrude yields (on average 15\% reduction for the binary mixtures and $40 \%$ for the ternary mixture), when comparing with linear averaging of the results for the separate feeds. From the feeds studied, the use of microalgae gives the highest crude yields (almost double the amount for pine wood), with the largest fraction of heavies but also the highest nitrogen content in the oil. When used in mixtures, a more than proportional part of the biocrude formed appears algal biomass based.

The significant deviations of the predictions in biocrude yield by the linear averaging model underline that more indepth studies are needed to unravel the interactions occurring during co-feeding different biomasses. Despite the lack of an accurate model, mixing different feeds seems a simple method to overcome the seasonality and the variations in availability and quality of biomass resources, thereby enabling hydrothermal liquefaction to become a biorefinery platform technology, able to benefit from "economy of scale" effects.

Open Access This article is distributed under the terms of the Creative Commons Attribution 4.0 International License (http:// creativecommons.org/licenses/by/4.0/), which permits unrestricted use, distribution, and reproduction in any medium, provided you give appropriate credit to the original author(s) and the source, provide a link to the Creative Commons license, and indicate if changes were made.

\section{References}

1. Lopez Barreiro D, Prins W, Ronsse F, Brilman W (2013) Hydrothermal liquefaction (HTL) of microalgae for biofuel production: state of the art review and future prospects. Biomass Bioenergy 53:113-127

2. Garcia Alba L, Torri C, Samorí C, van der Spek J, Fabbri D, Kersten SRA, Brilman DWF (2012) Hydrothermal treatment
(HTT) of microalgae: evaluation of the process as conversion method in an algae biorefinery concept. Energy Fuel 26:642657

3. Torri C, Garcia Alba L, Samorí C, Fabbri D, Brilman DWF (2012) Hydrothermal treatment (HTT) of microalgae: detailed molecular characterization of HTT oil in view of HTT mechanism elucidation. Energy Fuel 26:658-671

4. Biller P, Ross AB (2011) Potential yields and properties of oil from the hydrothermal liquefaction of microalgae with different biochemical content. Bioresour Technol 102:215-225

5. Leow S, Witter JR, Vardon DR, Sharma BK, Guest JS, Strathmann TJ (2015) Prediction of microalgae hydrothermal liquefaction products from feedstock biochemical composition. Green Chem 17: 3584-3599

6. Vardon DR, Sharma BK, Scott J, Yu G, Wang Z, Schideman L, Zhang Y, Strathmann TJ (2011) Chemical properties of biocrude oil form the hydrothermal liquefaction of Spirulina algae, swine manure and digested anaerobic sludge. Bioresour Technol 102: $8295-8303$

7. Demirbas A (2000) Effect of lignin content on aqueous liquefaction products of biomass. Energy Conversion \& Management 41:1601-1607

8. Pedersen TH et al (2016) Continuous hydrothermal co-liquefaction of aspen wood and glycerol with water phase recirculation. Appl Energy 162:1034-1041

9. Chen W-T, Zhang Y, Zhang J, Schideman L, Yu G, Zhang P, Minarick M (2014) Co-liquefaction of swine manure and mixedculture algal biomass from a wastewater treatment system to produce bio-crude oil. Appl Energy 128:209-216

10. Xiu S, Shahbazi A, Wang L (2016) Co-liquefaction of swine manure with waste vegetable oil for enhanced bio-oil production. Energy Sources, Part A: Recovery, Utilization, and Environmental Effects 38(4):459-465

11. Oudenhoven SRG, Westerhof RJM, Kersten SRA (2015) Fast pyrolysis of organic acid leached wood, straw, hay and bagasse. J Analytical Applied Pyrolysis 116:253-262

12. Zieminski $\mathrm{K}$ et al (2014) Effects of hydrothermal pretreatment of sugar beet pulp for methane production. Bioresour Technol 166: 187-193

13. Domalski ES, Jobe TLJ, Milne TA (1987) Thermodynamic data for biomass conversion and waste incineration. American Society of Mechanical Engineers, New York

14. Ramos-Tercero EA, Bertucco A, Brilman DWF (2015) Process water recycle in hydrothermal liquefaction of microalgae to enhance bio-oil yield. Energy Fuel 29:2422-2430

15. Li C, Yang X, Zhang Z, Zhou D, Zhang L, Zhang S, Chen J (2013) Hydrothermal liquefaction of desert shrub Salix Psammophila to high value-added chemicals and hydrochar with recycled processing water. Bioresources 8(2):2981-2997 